\title{
EFEKTIVITAS LAYANAN KONSELING KELOMPOK DENGAN PENDEKATAN BEHAVIORAL MELALUI TEKNIK SHAPING UNTUK MENGURANGI PROKRASTINASI AKADEMIK \\ SISWA KELAS VIII SMP NEGERI 2 BARAT KABUPATEN MAGETAN
}

\author{
Elly Ernawati *) \\ ernawati@yahoo.co.id \\ Vitalis Djarot Sumarwoto **) \\ vitalisdjarot@yahoo.co.id
}

\begin{abstract}
Abstrak
Prokrastinasi akademik adalah suatu kecenderungan penundaan tugas yang dilakukan secara terus-menerus oleh seseorang dan lebih memilih melakukan aktivitas lain yang kurang bermanfaat bagi dirinya. Perilaku siswa tersebut pada hakikatnya dapat berdampak pada aspek sosial, psikologis, maupun akademik, yang berujung pada terhambatnya perkembangan maupun pencapaian tujuan pendidikan. Ditinjau dari aspek sosial sangat mungkin siswa tidak memperoleh simpati dari teman-teman atau dijauhkan dari interaksi pergaulan. Ditinjau dari aspek psikologis perilaku prokastinasi bisa mengganggu aktivitas belajar dan kinerja yang diperlukan dalam mencapai tujuan pembelajaran. Secara akademik perilaku prokastinasi dapat menghambat bidang akademik, khususnya dalam mewujudkan prestasi-prestasi belajar di sekolah.

Bertolak dari uraian di atas maka perlu segera dicarikan solusinya agar tidak menghambat perkembangan dan pencapaian prestasi belajar siswa di sekolah. Salah satu solusi terhadap masalah di atas adalah dengan memberikan layanan konseling kelompok berbantuan dengan pendekatan behavioral melalui teknik shaping. Hakikat layanan konseling kelompok adalah layanan konseling yang memungkinkan konseli (siswa) memperoleh kesempatan untuk membahas dan mengentaskan masalah yang dihadapinya melalui dinamika kelompok.

Inti pokok pendekatan behavioral adalah penggunaan metode ilmiah dalam bidang psikoterapi, dengan memodifikasi perilaku melalui rekayasa lingkungan sehingga terjadi proses belajar untuk perubahan tingkah laku. Teknik shaping merupakan prosedur yang digunakan untuk membentuk perilaku individu (siswa) yang diinginkan dengan memberikan reinforcement pada setiap tingkah laku yang ditampilkan. Melalui terapi layanan konsdeling kelompok dengan pendekatan behavioral melalui teknik shaping hakikatnya adalah bahwa bantuan pemecahan masalah yang dilakukan secara kelompok dari seorang konselor yang ditujukan kepada individu (siswa) dengan harapan akan terjadi perubahan tingkah laku. Selanjutnya siswa yang telah berubah perilakunya setelah diberi terapi kemudian diberi reinforcement. Perilaku yang diupayakan dan diharapkan mengalami perubahan adalah berkurangnya kecenderungan menunda tugas yang dibebankan kepada konseli (siswa), yang dilakukan secara terus-menerus.
\end{abstract}

Kata Kunci: Konseling kelompok dengan pendekatan behavioral melalui teknik shaping dan Prokrastinasi akademik

* Ely Ernawati adalah Mahasiswa Program Studi Bimbingan dan Konseling Fakultas Ilmu Pendidikan IKIP PGRI MADIUN.

** Vitalis Djarot Sumarwoto adalah Dosen Program Studi Bimbingan dan Konseling Fakultas Ilmu Pendidikan IKIP PGRI Madiun. 


\section{PENDAHULUAN}

Prokrastinasi sering diartikan sebagai suatu kecenderungan penundaan tugastugas yang dibebankan kepada seseorang, dan dilakukan oleh secara terus-menerus. Penundaan tersebut dilakukan secara terus-menerus, dan lebih memilih melakukan aktivitas lain yang tidak berguna. Dampak yang langsung dirasakan adalah tidak produktif dan kinerjanya menjadi terhambat.

Perilaku prokastinasi ini ditemukan pada siswa kelas VIII SMP Negeri 2 Barat Kabupaten Magetan. Bentuk prokastinasi itu terkait dengan seringnya siswa melakukan penundaan untuk memulai dan menyelesaikan tugas-tugas sekolah, kesenjangan waktu antara rencana dan kinerja aktual serta melakukan aktivitas yang lebih menyenangkan.

Berdasarkan diagnosis yang dilakukan peneliti pada bulan Agustus tahun 2016, dengan menyebar angket awal diperoleh informasi bahwa siswa kelas VIII SMP Negeri 2 Barat Magetan memiliki sikap prokrastinasi akademik yang cukup tinggi. Pernyataan di atas didukung dengan dokumentasi yang dimiliki oleh fihak konselor sekolah. Prokrastinasi dalam penelitian ini lebih ditekankan pada penundaan siswa dalam hal mengerjakan tugas rumah (PR) yang diberikan oleh guru mata pelajaran disekolah.

Berdasarkan hasil isian angket awal diketahui bahwa terdapat 74 siswa atau $60 \%$ dari total siswa yang berjumlah 124 , mengalami permasalahan prokrastinasi akademik. Hasil isian angket menunjukkan bahwa dari jumlah 74 siswa tersebut dapat diklasifikasikan sebaga berikut: 10 siswa memiliki masalah prokastinasi akademik tinggi, 24 orang siswa memiliki masalah prokastinasi akademik sedang, dan 40 orang siswa yang memiliki masalah prokastinasi akademik rendah. Penelitian ini lebih memfokuskan pada 10 siswa yang bermasalah prokastinasi akademik yang tinggi, diasumsikan jika masalah tersebut tidak segera dicarikan solusi akan mengganggu perkembangan hidupnya dan menghambat pencapaian tujuan pendidikan. Dengan demikian sejumlah 10 orang siswa tersebut sekaligus ditetapkan sebagai sampel penelitian.

Berdasarkan hasil wawancara terhadap 10 siswa yang mempunyai masalah prokastinasi akademik tinggi dalam penyelesaian tugas rumah (PR) 
diperoleh informasi bahwa penyebabnya antara lain adalah: $42,4 \%$ siswa menyatakan tidak memahami tugas rumah, 16,6\% kurang perhatian terhadap aktivitas sekolah, 23,8\% menyatakan percuma dikerjakan karena tidak diperhitungkan sebagai nilai raport, 17,2\% siswa tidak menggunakan waktu luangnya untuk aktivitas belajar. Pernyataan diatas didukung hasil penelitian dari Yuanita (dalam Aliya dan Iranita, 2011: 66) yang menyatakan sebanyak $70 \%$ pelajar banyak yang bermasalah dalam prokrastinasi akademik.

Timbulnya perilaku prokastinasi akademik pada diri siswa, khususnya yang berkaitan dengan tugas rumah (PR) tersebut lebih banyak disebabkan karena adanya pengaruh faktor ekternal siswa. Faktor eksternal yang dimaksud dalam penelitian ini adalah pengaruh temanteman sebayanya di sekolah, kurangnya pengawasan orang tua atau keluarga. Di sisi lain adalah kondisi lingkungan sekitar yang mendukung berkembangnya perilaku prokrastinasi akademik. Hal lain yang mempengaruhi siswa dalam melakukan penundaan tugas ialah bentuk pengajaran yang kurang inovatif sehingga siswa menjadi malas belajar, yang berakibat pada menurunnya nilai akademik siswa.
Solomon dan Rothblum menyatakan bahwa hakikat prokrastinasi adalah kecenderungan menunda untuk memulai maupun menyelesaikan pekerjaan atau tugas-tugas, dan lebih tertarik melakukan aktivitas lain, yang tidak bermanfaat bagi perkembangan diri, sehingga menghambat kinerja, menyelesaikan tugas-tugas tidak pernah tepat waktu, serta sering terlambat dalam menghadiri pertemuan-pertemuan (Aini dan Mahardayani, 2011: 65). Ahli lain berpendapat bahwa kecenderungan menunda pekerjaan atau tugas-tugas merupakan godaan bagi setiap orang (Spillane, 2003: 99).

Kecenderungan menunda tugas atau pekerjaan yang menjadi ciri khas dalam masalah prokastinasi bisa terjadi karena: (1) tanpa alasan, bisa jadi dengan niat baik namun tidak terwujud, (2) berkembang menjadi sumber stress, rasa bersalah, rusaknya kerjasama, dan (3) menipu diri sendiri.

Atas dasar uraian di atas maka peneliti merasa perlu segera memberikan bantuan pemecahan terhadap masalah yang dihadapi siswa tersebut. Menurut asumsi peneliti, siswa yang mengalami masalah prokastinasi akademik tersebut akan berubah perilakunya apabila diberikan layanan konseling kelompok dengan pendekatan behavioral melalui 
teknik shaping. Melalui kegiatan konseling kelompok tersebut siswa dapat memecahkan masalah yang dihadapi.

Hakikat layanan konseling kelompok menurut Amin (2010: 292) adalah bantuan yang berupa layanan konseling yang memungkinkan konseli memperoleh kesempatan untuk pembahasan dan penuntasan masalah yang dialaminya melalui dinamika kelompok. Pendapat di atas didukung oleh pandangan Tohirin (2011: 179) yang menyatakan bahwa layanan konseling kelompok merupakan upaya pemberian bantuan kepada individu atau siswa yang mengalami masalah-masalah pribadi melalui kegiatan kelompok agar tercapai perkembangan yang optimal. Dinamika pemecahan masalah yang dihadapi siswa dapat lebih efektif dan efisien jika dalam melakukan proses konseling kelompok anggota kelompok memiliki pemahaman dan pengaktualisasian teknik-teknik konseling. Salah satu teknik yang dikembangkan dalam layanan konseling kelompok yang sesuai dengan karakteristik masalah prokastinasi akademik adalah dengan pendekatan behavioral.

Pendekatan behavioral adalah metode ilmiah dalam bidang psikoterapi yaitu dengan cara memodifikasi perilaku melalui rekayasa lingkungan, sehingga terjadi proses belajar untuk suatu perubahan tingkah laku Willis (2011: 105). Senada dengan pendapat Willis dikemukakan oleh Willis, (2012: 24) yang menyatakan bahwa pendekatan behavior merupakan suatu pandangan ilmiah tentang tingkah laku manusia, tingkah laku manusia merupakan hasil belajar, dipengaruhi oleh lingkungan dan merupakan modifikasi tingkah laku. Tujuan utama yang ingin dicapai melalui pendekatan behavioral adalah:

fokusnya pada perilaku yang tampak dan spesifik, (2) kecermatan dan penguraian tujuan-tujuan treatment, (3) formulasi prosedur treatment khusus sesuai dengan masalah-masalah khusus, dan (4) penilaian objektif mengenai hasil konseling (Willis, 2011: 105).

Pendekatan behavioral itu sendiri pada dasarnya secara inklusif memuat beberapa teknik yang cocok untuk diterapkan, salah satunya adalah teknik shapig. Inti dari teknik shaping adalah metode atau cara membantu mengurangi masalah prokastinasi akademik, khususnya penundaan terhadap penyelesaian tugas-tugas rumah. Oleh karena itu penggunaan teknik shaping dalam pendekatan behavioral menjadi efektif. Hal itu terjadi karena antara pendekatan behavior dengan teknik shaping mempunyai tujuan yang sama, 
yaitu memunculkan perilaku baru pada diri siswa, yang diperoleh dari hasil belajar. Pernyataan tersebut sesuai dengan pendapat Komalasari, dkk. ( 2011: 169) yang menyatakan bahwa teknik shaping adalah cara membentuk tingkah laku baru yang belum ditampilkannya, yaitu dengan memberi reinforcement secara sistematik dan langsung setiap kali tingkah laku ditampilkan.

Penggunaan layanan konseling kelompok dengan pendekatan behavioral melalui teknik shaping untuk mengubah perilaku siswa juga didukung dengan adanya jurnal penelitian Putra, Suranata, Dharsana (2014: 9), yang menyatakan bahwa konseling behavioral dengan teknik shaping mampu mengubah perilaku seseorang (siswa) sesuai dengan yang diinginkan. Pendapat serupa dikemukakan Rahmawati (2009: 20), yang menyatakan bahwa teknik shaping adalah teknik ang digunakan dalam memroses penguasaan respon yang dikehendaki atau dikondi-sikan. Pengkondisian tersebut dilakukan ketika pembentukan perilaku merupakan pemberian reinforcement setelah sukses melakukan apa yang diinginkan melewati serangkaian perilaku yang diulang untuk menjadi lebih baik lagi.
Menurut Komalasari, dkk. (2011: 170) terdapat beberapa langkah dalam menjalankan tekhnik shaping, yaitu: (1) membuat analisis $\mathrm{ABC}$, (2) menetapkan target perilaku spesifik yang akan dicapai bersama konseli/siswa, (3) menentukan bersama jenis reinforcement positif yang akan digunakan, (4) membuat perencanaan dengan membuat tahapan pencapaian perilaku mulai dari perilaku awal sampai akhir, (5) perencanaan dapat dimodifikasi selama berlangsungnya program shaping, (6) penetapan waktu pemberian reinforcement pada setiap tahap program.

Pernyataan di atas memberi petunjuk bahwa pemberian layanan konseling kelompok dengan pendekatan behavioral melalu iteknik shaping dapat membentuk perilaku baru sehingga mengurangi prokrastinasi akademik. Atas dasar asumsi dasar tersebut maka peneliti tertarik untuk mengkaji masalah dalam penelitian ini dengan lebih mendalam, dengan mengemukakan judul: "Efektivitas layanan konseling kelompok dengan pendekatan behavioral melalui teknik shaping untuk mengurangi prokrastinasi akademik. Subyek peneliti adalah siswa Kelas VIII SMP Negeri 2 Barat Kabupaten Magetan.

METODE PENELITIAN 
Penelitian menggunakan metode penelitian eksperimen. Rancangan penelitian sesuai dengan pendapat Sugiyono (2013: 107) yang menjelaskan bahwa metode penelitian eksperimen adalah metode penelitian yang digunakan untuk mencari pengaruh perlakuan (treatment) tertentu terhadap hal lain dalam kondisi yang terkendali. Jadi penggunaan metode eksperimen ini telah memenuhi persyaratan metodologis. Desain penelitian eksperimen yang dikembangkan dalam penelitian ini adalah One Group Pre test-Post test Design.

Penetapan sampel penelitian menggunakan teknik purposive sampling. Teknik purposive sampling dipilih dengan suatu pertimbangan bahwa peneliti telah mengetahui ciri-ciri atau sifat-sifat tertentu dari populasi. Pernyataan ini didukung oleh pendapat Sutrisno Hadi (dalam Vitalis, 2015: 17) yang menyatakan bahwa "Pelaksanaan teknik purposive sampling adalah menentukan sekelompok individu atas dasar ciri-ciri atau sifat-sifat tertentu yang dipandang memiliki keterkaitan dengan ciri-ciri atau sifat-sifat tertentu populasi yang telah diketahui sebelumnya". Ciri tersebut antara lain siswa yang dijadikan sampel penelitian duduk di kelas yang sama, usia mereka kurang lebih sama. Sifat yang melekat pada diri siswa, seperti mereka sedang memasuki periode perkembangan yang sama.

Pengumpulan data prokastinasi akademik menggunakan teknik angket, yang disusun dalam bentuk pilihan ganda, dengan empat alternatif jawaban : a (Selalu), b (Sering), c (Kadang-kadang, dan d (Tidak Pernah). Jumlah item angket disediakan adalah sebanyak 20 butir item. Analisis data penelitian menggunakan metode statistik denga rumus t-score.

Penyusunan angket penelitan ini mengacu pada pola Skala Likert (Sugiyono 2013: 134). Penyusunan item angket mendasaran pada kisi-kisi, yang berfungsi sebagai indikator item sebagai berikut:

Tabel 1. Kisi-kisi Angket Prokastinasi Akademik

\begin{tabular}{|c|l|c|c|}
\hline No. & \multicolumn{1}{|c|}{ Indikator Item } & $\begin{array}{c}\text { Distribusi } \\
\text { nomor item }\end{array}$ & $\sum$ \\
\hline 1 & Penundaan memulai dan menyelesikan tugas & $1,3,5$, & 5 \\
& sekolah & 7,15 & \\
\hline 2 & Ketepatan mengumpulkan tugas sekolah & $2,4,6$, & 5 \\
& & 8,16 & \\
\hline 3 & Kesenjangan waktu antara rencana kerja dan & $9,11,13$, & 5 \\
& kinerja akatual & 15,17 & \\
\hline
\end{tabular}




\begin{tabular}{|l|llc|c|c|}
\hline 4 & $\begin{array}{l}\text { Melakukan aktivitas yang lebih } \\
\text { menyenangkan }\end{array}$ & $\begin{array}{c}10,12,14, \\
18,20\end{array}$ & 5 \\
\hline \multicolumn{2}{|c|}{$\sum$} & 20 & 20 \\
\hline
\end{tabular}

Uji validitas butir item menggunakan rumus korelasi product moment dengan angka kasar sebagaimana yang dikemukakan Arikunto (2013: 213) sebagai berikut:

$r_{x y}=\frac{N \sum X Y-\left(\sum X\right)\left(\sum Y\right)}{\sqrt{\left\{N \sum X^{2}-\left(\sum X\right)^{2}\right\}\left\{N \sum Y^{2}-\left(\sum Y\right)^{2}\right\}}}$

Keterangan:

$$
\begin{aligned}
\boldsymbol{r}_{x y}= & \text { koefisien korelasi antara skor } \\
& \text { item dengan skor total } \\
\sum x y= & \text { jumlah hasil perkalian skor item } \\
\sum x \quad= & \text { skor butir } \\
\sum y \quad= & \text { skor total } \\
\mathrm{N} & =\text { banyaknya subjek }
\end{aligned}
$$

Kriteria : Jika r-hitung > r-tabel, item dinyatakan valid, dengan $\mathrm{TS}=5 \%$

Uji reabilitas butir item angket dilakukan menggunakan rumus Alpha sebagai berikut:

$$
\mathrm{r}_{11}=\left(\frac{k}{k-1}\right)\left(1-\frac{\Sigma \sigma_{b^{2}}}{\sigma_{t}^{2}}\right)
$$

\section{HASIL PENELITIAN}

\section{Uji Validitas dan Reliabilitas}

a. Uji Validitas

Uji validitas butir item angket prokastinasi akademik antara sebelum dan setelah diberi
(Arikunto, 2013:239)

Keterangan:

$\mathrm{r}_{11}=$ Reabilitas instrumen

$k=$ Banyak butir pertanyaan

$\Sigma \sigma_{b^{2}}=$ Jumlah varians butir

$\Sigma_{\mathrm{t}}^{2}=$ Varians total

Varians butir

$\sigma_{b^{2}}=\frac{\sum x^{2}-\frac{\left(\sum x\right)^{2}}{n}}{n}$

Varians total

$\sigma_{t^{2}}=\frac{\sum Y^{2}-\frac{\left(\sum Y\right)^{2}}{n}}{n}$

Keterangan :

$$
\begin{aligned}
\sigma_{b^{2}} & =\text { Varians butir } \\
\sigma_{t^{2}} & =\text { Varians total } \\
\mathrm{X} & =\text { Skor butir } \\
\mathrm{Y} & =\text { Skor total } \\
\mathrm{n} & =\text { Jumlah subyek }
\end{aligned}
$$

Kriteria: Jika r-hitung > r tabel maka item dinyatakan reliabel.

treatment menggunakan rumus rumus product moment.

Kriteria untuk menguji butir angket adalah nilai $r_{x y}>0,444$. Hasil uji validfitas butir angket angket prokastinasi sebanyak 20 item dinyatakan semuanya valid. 
b. Uji Reliabilitas

Uji rteliabilitas butir angket prokastinasi

akademik

menggunakan rumus Alpha, angket dikatakan reliabel jika $r_{11}>0,444$. Hasil yang diperoleh adalah bahwa $r_{11}=0,98$, sedangkan $\mathrm{r}$ tabel $5 \%=0,444$, sehingga semua adalah reliable. Oleh sebab itu semua butir item angket prokastinasi akademik dinyatakan reliabel.

\section{Deskripsi Data}

a. Deskripsi data skor hasil isian angket prokastinasi akademik sebelum

diberi layanan konseling kelompok dengan pendekatan behavioral melalui tekik shaping

Analisis data menggunakan bantuan program Microsoft Office Excle release 12 tahun 2015, dengan $\mathrm{N}=10$, diperoleh hasil perhitungan sebagai berikut: Mean $=56,7 ;$ Modus $=55 ;$ Median $=55,5 ; \mathrm{SD}=3,713 ;$ Skor maksimal $=62$; dan skor minimal $=52$.

Atas dasar data di atas disusun tabel sebagai berikut:

Tabel 2. Skor hasil isian angket prokastinasi akademik sebelum diberi layanan konseling kelompok dengan pendekatan behavioral melalui tekik shaping.

\begin{tabular}{|c|c|c|c|}
\hline $\begin{array}{c}\text { No. } \\
\text { Sbyk }\end{array}$ & I & Yi & f \\
\hline 1 & $61-63$ & 62 & 2 \\
\hline 2 & $58-60$ & 59 & 2 \\
\hline 3 & $55-57$ & 56 & 3 \\
\hline 4 & $52-54$ & 53 & 3 \\
\hline
\end{tabular}

b. Deskripsi data skor hasil isian angket prokastinasi akademik setelah diberi

layanan konseling kelompok dengan pendekatan behavioral melalui tekik shaping

Analisis data menggunakan bantuan program Microsoft Office Excel Release 12 tahun 2015, dengan $\mathrm{N}=10$, diperoleh hasil perhitungan sebagai berikut: Mean $=74,7 ;$ Modus $=75 ;$ Median $=78,5 ; \mathrm{SD}=3,917 ;$ Skor maksimal $=79 ;$ dan skor minimal $=65$.

Atas dasar data di atas disusun tabel sebagai berikut:

Tabel 3. Skor hasil isian angket prokastinasi akademik setelah diberi layanan konseling kelompok dengan pendekatan behavior melalui tekik shaping.

\begin{tabular}{|c|c|c|c|}
\hline $\begin{array}{c}\text { No. } \\
\text { Sbyk }\end{array}$ & I & Xi & f \\
\hline 1 & $77-79$ & 78 & 3 \\
\hline 2 & $74-76$ & 75 & 4 \\
\hline 3 & $71-73$ & 72 & 2 \\
\hline 4 & $68-70$ & 69 & 0 \\
\hline
\end{tabular}


\begin{tabular}{|l|l|l|l|}
\hline 5 & $65-67$ & 66 & 1 \\
\hline
\end{tabular}

\section{c. Hasil Perhitungan Statistik}

Bertolak dari skor angket prokastinasi akademik antara sebelum (X) dan setelah (Y) diberi layanan konseling kelompok dengan pendekatan behavior melalui teknik shaping, yang dihitung dengan bantuan program Microsoft Office Excel, Release 12 tahun 2015, maka data tersebut dapat ditabulasikan sebagai berikut:

Tabel 4. Perhitungan Pengaruh Prokastinasi Antara Sebelum dan Sesudah Diberi layanan Konseling Kelompok Dengan Pendekatan Behavioral Melalui Teknik Shaping Dengan Rumus T-Score

\begin{tabular}{|c|c|c|c|r|r|r|r|r|}
\hline $\begin{array}{c}\text { No. } \\
\text { Sbk }\end{array}$ & $\mathrm{I}$ & $\mathrm{Xi}$ & $\mathrm{f}$ & \multicolumn{1}{c|}{$\mathrm{fX}$} & \multicolumn{1}{c|}{$\mathrm{fX}^{2}$} & $\mathrm{f}$ & $\mathrm{fY}$ & \multicolumn{1}{c|}{$\mathrm{fY}^{2}$} \\
\hline 1 & $75-79$ & 77 & 5 & 385 & 29645 & 0 & 0,0 & 0,0 \\
\hline 2 & $70-74$ & 72 & 2 & 144 & 10368 & 2 & 144 & 10368 \\
\hline 3 & $65-69$ & 67 & 1 & 67 & 4489 & 3 & 201 & 13467 \\
\hline 4 & $60-64$ & 62 & 0 & 0,0 & 0,0 & 0 & 0,0 & 0,0 \\
\hline 5 & $55-59$ & 57 & 0 & 0,0 & 0,0 & 1 & 57 & 3249 \\
\hline 6 & $50-54$ & 52 & 1 & 52 & 2704 & 2 & 104 & 5408 \\
\hline 7 & $45-49$ & 47 & 1 & 47 & 2209 & 0 & 0,0 & 0,0 \\
\hline 8 & $40-44$ & 42 & 0 & 0,0 & 0,0 & 0 & 0,0 & 0,0 \\
\hline 9 & $35-39$ & 37 & 0 & 0,0 & 0,0 & 2 & 74 & 2738 \\
\hline Total & -- & -- & 10 & 695 & 49415 & 10 & 580 & 35230 \\
\hline
\end{tabular}

Berdasarkan tabel di atas kemudian dihitung dengan rumus t-score sebagai berikut:

$$
\mathrm{t}=\frac{M_{x}-M_{y}}{S D_{b m}}
$$

Keterangan :

$\mathrm{t} \quad=$ Taraf Kepercayaan

Mx = Mean dari kelompok sebelum mendapatkan treatment
My = Mean dari kelompok setelah mendapatkan treatment

$\mathrm{SD}_{\mathrm{bm}}=$ Standart kesalahan perbedaan mean

(Hadi, 2001: 268)

Diketahui:

$\mathrm{Nx}=10$

$\mathrm{Ny}=10$

$\sum \mathrm{fX}=695$

$\sum$ fy $=580$ 


$$
\sum \mathrm{fX}^{2}=49.415
$$

\section{Perhitungan:}

$$
\begin{aligned}
\mathrm{M}_{\mathrm{x}} & =\left(\sum \mathrm{fX}: \mathrm{N}\right)=569: 10=56,9 \\
\mathrm{SD}_{\mathrm{x}}{ }^{2} & =\left(\sum \mathrm{SD}_{\mathrm{x}}{ }^{2}: \mathrm{N}\right)-\mathrm{M}_{\mathrm{x}}{ }^{2}=(32.587: 10)-(56,9)^{2} \\
& =3.258,7-3.237,6=21,1 \\
\mathrm{SD}_{\mathrm{Mx}}{ }^{2} & =\sum \mathrm{SDx}^{2}:(\mathrm{N}-1)=21,1: 9=2,34 \\
\mathrm{M}_{\mathrm{y}} & =\left(\sum \mathrm{fY}: \mathrm{N}\right)=747: 10=74,7 \\
\mathrm{SD}_{\mathrm{y}}{ }^{2} & =\left(\sum \mathrm{fY}^{2}: \mathrm{N}\right)-\mathrm{M}_{\mathrm{y}}{ }^{2}=(55.961: 10)-(74,7)^{2} \\
& =5.596,1-5.490,8=105,3 \\
\mathrm{SD}_{\mathrm{My}}{ }^{2} & =\sum \mathrm{SDy}^{2}:(\mathrm{N}-1)=105,3: 9=11,7 \\
\mathrm{SD}_{\mathrm{bM}} & =\sqrt{2,34+11,7}=\sqrt{14,04}=3,747 \text { (dibulatkan) } \\
\mathrm{t} & =\frac{(74,7-56,9)}{3,747}=\frac{17,8}{3,747}=4,751
\end{aligned}
$$

Bertolak dari hasil perhitungan di atas diketahui bahwa t-hitung sebesar 4,751. Setelah dikonsultasikan dengan harga t-tabel, dengan $\mathrm{N}=10$, dan d.b $=\mathrm{N}-1$, maka dapat dinyatakan bahwa t-hitung > ttabel $(4,751>2,262 / \mathrm{TS}=5 \%$ dan $2,821 / \mathrm{TS}=1 \%$ ), maka dinyatakan signifikan.

Simpulan hipotesis: "Konseling kelompok dengan pendekatan behavior melalui teknik shaping adalah efektif digunakan untuk mengurangi prokrastinasi akademik siswa kelas VIII SMPN 2 Barat Kabupaten Magetan tahun pelajaran 2015/2016.

\section{PEMBAHASAN}

Hasil penelitian di lapangan menunjukkan bahwa 10 dari 211 siswa kelas VIII SMP Negeri 2 Barat Kabupaten Magetan yang terindikasi memiliki masalah prokrastinasi akademik yang tinggi. Masalah prokastinasi akademik dalam penelitian ini lebih 
difokuskan pada menunda penyelesaian tugas rumah (PR) dari sekolah.

Hasil analisis data penelitian menunjukkan bahwa t-hitung sbeesar 4.751, yang menunjukkan lebih besar apabila dibandingkan dengan harga $\mathrm{t}$ tabel $=2,262 /$ TS5\%. Bertolak dari hasil analisis data penelitian disimpulkan bahwa konseling kelompok dengan pendekatan behavioral melalui teknik shaping sangat efektif untuk mengurangi prokastinasi akademik siswa. Pernyataan tersebut memberi petunjuk bahwa layanan konseling kelompok dengan pendekatan behavior melalui teknik shaping sangat tepat dan efisien dalam mengurangi prokrastinasi akademik. Hal tersebut telah sesuai dengan hakikat konseling kelompok behavioral merupakan pendekatan dalam dunia konseling yang diarahkan untuk aktivitas belajar, yang menghasilkan perubahan tingkah laku. Perubahan tingkah laku siswa lebih ditingkatkan ketika diberi treatmen dengan teknik shaping. Pernyataan tersebut sesuai dengan pendapat Tohirin (2011: 179) yang menyatakan bahwa layanan konseling kelompok merupakan upaya pemberian bantuan kepada individu (siswa) yang mengalami masalah-masalah pribadi melalui kegiatan kelompok agar tercapai perkembangan yang optimal. Pernyataan di atas didukung oleh pandangan Amin (2010: 292) yang menyatakan bahwa bantuan dalam layanan konseling yang memungkinkan konseli memperoleh kesempatan untuk pembahasan dan penuntasan masalah yang dialaminya melalui dinamika kelompok. Melalui dinamika kelompok itu pemecahan masalah dapat lebih efektif dan efisien jika dalam melakukan proses konseling kelompok anggota kelompok memiliki pemahaman dan pengaktualisasian teknik-teknik konseling.

Inti utama terapi dengan teknik shaping adalah penerapan aneka ragam teknik dan prosedur yang berakar pada berbagai teori belajar. Pendekatan ini telah memberikan penerapan yang sistematis tentang prinsip-prinsip belajar dan pengubahan tingkah laku ke arah cara-cara yang lebih adaptif.

Berdasarkan uraian di atas jelas bahwa masalah prokastinasi akademik, khususnya penundaan penyelesaian tugas rumah (PR) dari sekolah dapat diprediksi dari layanan konseling kelompok dengan pendekatan behavior melalui teknik shaping.

\section{Simpulan dan Saran}

1. Simpulan 
Berdasarkan hasil penelitian dan hasil analisis data maka disimpulkan sebagai berikut:

a. Layanan konseling kelompok dengan pendekatan behavior melalui teknik shaping efektif diterapkan untuk mengurangi prokrastinasi akademik siswa kelas VIII SMPN 2 Barat Kabupaten Magetan.

b. Terdapat penurunan yang signifikan perilaku prokrastinasi akademik setelah diberi layanan konseling kelompok dengan pendekatan behavioral melalui teknik shaping, khususnya pada siswa kelas VIII di SMPN 2 Barat Kabupaten Magetan.

2. Saran

Atas dasar simpulan di atas maka dikemukakan saran sebagai berikut: pihak sekolah secara kolegial dapat menyelenggarakan program bimbingan belajar dengan cara menerapkan layanan konseling kelompok dengan pendekatan behavioral melalui teknik shaping. Kegiatan bimbingan belajar dapat dilakukan secara bersama-sama oleh pihak guru bidang studi dengan konselor sekolah. Di sisi lain program layanan konsleing kelompok dapat pula dikembangkan melalui dinamika kelompok untuk bebrapa mata pelajaran, yang sama karakteristiknya. Pada akhir kegiatan sebaiknya dievaluasi untuk mengetahui efektivitasnya.

\section{DAFTAR PUSTAKA}

Aini, Aliya Noor dan Iranita Hervi Mahardayani. 2011. Hubungan Antara Kontrol Diri Dengan Prokrastinasi Dalam Menyelesaikan Skripsi Pada Mahasiswa Universitas Muria Kudus. Jurnal Psikologi Pitutur (Online), Vol. 1, No. 2, (http://eprints.undip.ac.id/, Diunduh 19 Februari 2015).

Amin, S. M. 2010.Bimbingan dan Konseling Islam. Jakarta: Amzah.

Arikunto, Suhasimi. 2010. Prosedur Penelitian Suatu Pendekatan Praktik. Jakarta: Rineka Cipta.

Hadi, Sutrisno. 2001. Statistik II. Yogjakarta: Pustaka Belajar.

Komalasari dkk., 2011. Teori dan Teknik Konseling. Jakarta: Indeks.

Putra, W.A.S, Suranata K. Dharsana I.K .2014. Penerapan konseling behavioral dengan teknik shaping untuk meningkatkan disiplin belajar. Jurnal Bimbingan dan Konseling (online), Volume 2 No. 1 (http://ejournal. undiksha.ac.id/ index.php/JJBK/article/viewFile/3 710/2969, Diunduh 20 Maret 2015).

Rahmawati, Hetty. 2009. Modifikasi Perilaku Manusia. Malang: Universitas Negeri Malang.

Spillane, J. J. 2007. Time Management. Yogyakarta: Kanisius.

Sugiyono. 2013. Metode Penelitian Pendidikan Pendekatan 
Kuantitatif, Kualitatif dan R\&D. Bandung : Alfabeta.

Tohirin. 2011. Bimbingan dan Konseling Sekolah dan Madrasah. Jakarta: Raja Grafindo Persada.
Vitalis, 2015. Statistik Inferensial. Madiun: IKIP PGRI Madiun, Fakultas Ilmu pendidikan.

Wilis, S. S. 2011. Konseling Keluarga. Bandung: Alfabeta. 